\title{
Possibilities of receptive music therapy (RMT) for mothers raising children with developmental disorders as a self-help tool for overcoming stress during the COVID-19 pandemic
}

\author{
Jautre Ramute Sinkuniene ${ }^{1}$ and Jurgita Zalgiryte-Skurdeniene ${ }^{2}$ \\ ${ }^{1}$ Mykolas Romeris University, Vilnius, Lithuania \\ ${ }^{2}$ Vilnius University, Lithuanian Academy Of Music And Theatre, Vilnius, Lithuania
}

\begin{abstract}
After the announcement of quarantine due to Covid-19 on March 16, 2020, parents of children with disabilities were left without help from educational and health professionals, while changes in routine, work and financial restrictions, isolation, exacerbations of children's mental disorders increased the level of parental anxiety, tension, fear and anger. Research on music therapy conducted by the world scientists demonstrated the effectiveness of applying receptive music therapy (RMT) methods to cope with stress, when listening to music is used as a tool that can change the client's state and help to reveal one's experiences. The aim of the article is to reveal, theoretically and empirically, possibilities of remote application of receptive music therapy for mothers raising children with developmental disorders. Tasks: 1) to present a model of remote application of receptive music therapy for coping with stress; 2) to examine the possibilities of independent application of the developed therapeutic instrument for client's self-help. Problem question: how can mothers use the therapeutic tool and skills acquired during the receptive music therapy on their own during the Covid-19 quarantine? The mixed data collection methodology was chosen for the research: 1) in-depth, semi-structured interview (content analysis method); 2) Perceived Stress Scale (PSS) questionnaire; 3) Musical Life Panorama (MLP) biographical interview; 4) Audio recordings of music therapy sessions - qualitative narrative analysis; 5) Music Listening Diary (MLD). Fours subjects were selected on a voluntary participatory basis by forming a homogenous group according to a similar experience of raising children with disabilities. The research revealed that remote application of RMT improved the study participants' ability to recognize stressful situations better, feelings, and reactions arising during them, and helped them to understand their emotions better. The clients learned to apply the therapeutic instrument independently in order to relieve a stressful situation, adverse reactions, or the emerging emotions. With the formation of the habit of listening to music more often, not only did the ability to relax, not get upset, calm down was strengthened, but tension decreased and the general emotional background in the family improved. The application of RMT increased clients' ability to cope with stress and reduced the risk of recurring stressful situations. Study participants confirmed the suitability of RMT both in remote sessions and in self-application of the instrument for self-help after the therapy during the COVID-19 quarantine.
\end{abstract}




\section{Introduction}

The birth of a child with a disability, the diagnosis of a developmental disorder, and the upbringing of a special child are considered as chronic stresses that have a significant impact on the psychological well-being and quality of life in the family [1,2]. Peculiarities of stress experienced by parents of children with developmental disorders are examined in the research in various fields of science [3]: conflicting feelings and emotions, feeling of guilt, fear for the future of the child experienced by parents [4]; stressful fatigue, helplessness, sadness, anxiety, dissatisfaction with oneself [5] no longer seeing a way out of the situation, depression [6]. K. Ilias et al. [7] conducted a systematic analysis of the research results by 28 different authors, which revealed four main stressors for parents of children with disabilities: lack of social assistance; peculiarities of the child's disability; financial difficulties; the level of parental reconciliation with the situation and acceptance of the disability.

The level of stress experienced by parents is strongly influenced by the child's diagnosis [8]: families with a child with autism spectrum disorder (ASD) have a higher risk of psychological problems $[2,7,8,9,10,11]$ than other families. Constant psychological tension, anxiety, fears, feeling of guilt, anger, and despair make many parents of children with ASD prone to depression $[9,12,13]$. Hayes and Watson [14] confirm that families with children with ASD and Down syndrome experience higher levels of stress than the parents having children with other developmental disorders do $[15,16]$.

The results of the survey "Opinions of persons with disabilities in Lithuania on the assurance of rights of the disabled children and family support" (2019) revealed that more than half of families do not receive enough information about the development, education, communication features of a child with a disability, about services and financial assistance provided. About $77 \%$ of respondents do not receive help from a psychologist, $88 \%$ of respondents - consultations for brothers and sisters [17]. The lack of specialist assistance and services in Lithuania is identified in many studies as one of the most stressful factors for parents $[1,4,7,18,19]$.

With the spread of COVID-19 virus in Europe, Lithuania has announced a universal quarantine regime on March 16, 2020. The representative surveys of the Lithuanian population showed a strong emotional response to the crisis: the number of people experiencing anxiety increased almost 2.5 times (from $26.1 \%$ to $64.3 \%$ ), sadness - more than twice (from $21.9 \%$ to $46.8 \%$ ), anger - almost twice (from $19.8 \%$ to $35.6 \%$ ) [20]. According to a study conducted by the Ministry of Health in January 2021, the level of public stress in Lithuania is currently twice as high as before the COVID-19 pandemic: only $14 \%$ of the population felt stress before the pandemic, and with the onset of the pandemic the number has tripled.

Research problem. With the declaration of quarantine in Lithuania due to Covid-19, parents of children with disabilities were left without the help of education and health professionals, and the change of routine, work and financial constraints, isolation, exacerbations of mental health problems in children increased levels of parental anxiety, tension, fears, and anger. The World Health Organization, organizations that unite parents of children with disabilities, already in the first weeks distributed reports with recommendations on how to live in quarantine conditions, how to help children, how specialists should act [21, 22, 23]. Not only do parents of children with developmental disabilities face unavailability of specialists' help, but also challenges related to the child's well-being caused by sensory stimuli: wearing masks, gloves, hand disinfection, changes in routine. All of the mentioned factors cause exacerbations of inadequate, aggressive behaviour and health states of children, at the same time increasing the level of stress experienced by parents [21]. When specialists lost the possibility to help children and parents directly, problems in finding ways to provide assistance remotely appear. 
RMT for stress reduction is used due to the positive effect of listening to music on both physiological expression of stress - regulation of breathing, heart rate, pain relief, blood pressure and hormone level, and psychological stress experiences - reduction of tension, nervousness, fear and anxiety, to reduce stress before various medical procedures, to facilitate long stays in a medical institution, or to teach clients to relax by improving their psychosocial functioning [26, 27, 28, 29, 30, 31, 32], as well as for positive changes in human health and well-being [25, 27, 33, 34, 35]. According to De Vitte et al. [32], listening to music can distract from stressful thoughts or feelings. Taking into account the low cost and side effects of music interventions, the moderate sedative effects of music are crucial for the prevention and treatment of stress-related problems [31,32].

The "Plan for Reducing the Long-Term Negative Effects of the COVID-19 Pandemic on Mental Health" [24] indicates that as the COVID-19 pandemic continues and ends, there will be more challenges and negative consequences for public mental health. The World Health and Mental Health Organizations and international experts claim that it is necessary to take long-term measures to solve mental health problems caused by the COVID-19 pandemic, because the negative socio-economic consequences will be felt for a long time to come. $\mathrm{Mu}-$ sic Therapy (MT) can be one of the forms of complex support that could at least partially compensate for the lack of psychological support by contributing to the improvement of the mental health of parents of children with disabilities. The aim of the article is to reveal the possibilities of RMT in reducing stress experienced by mothers and by providing a self-help tool for coping with stress, which they may use independently after the end of therapy. The presented research on the application of receptive music therapy is the first scientific attempt in the following field in Lithuania.

The questions of the research: How developed model of short-term receptive music therapy corresponds to the need to strengthen mother's stress overcoming skills? How can the application of RMT increase the clients' ability to cope with stress and decrease the risk of recurrence of stressful situations? How can mothers independently use the therapeutic tool and skills acquired during the receptive music therapy in the period of the Covid-19 quarantine?

The object of the research - application of the receptive music therapy (RMT) instrument as a self-help tool for stress reduction.

The aim of the research is to reveal, theoretically and empirically, possibilities of remote application of receptive music therapy for mothers raising children with developmental disorders.

Tasks of the research:

- To present a model of remote application of receptive music therapy for overcoming stress; - To examine possibilities of the independent application of the developed therapeutic instrument of RMT for the client's self-help.

Research methods - theoretical analysis of scientific literature and documents; the mixed data collection methodology was chosen for the research.

\section{Receptive music therapy for overcoming stress}

Music therapy is the use of music interventions based on clinical research and practice, aimed at individualized goals through therapeutic connection with the help of a certified music therapist. Receptive music therapy (hereinafter: RMT) is the experience of the effects of music, using music as a tool that can affect or change the client's state, emotions and experiences. In the musical part of the RMT, music is differentiated according to the client's needs: a) for relaxation (calm and constant tempo, predictable, little dynamic changes) and b) for 
stimulation (dynamic, changing tempo of music, emotionally contrasting, variety of instrumentation). The verbal part of the RMT process is very important in order to discover and understand changes in the client's condition. For the following purpose, music therapist uses skills and practices that are commonly applied in psychological counselling or psychotherapy [25]. Taking into account the pace of life, high requirements of the modern society, the need for stress reduction interventions is and will be enormous. The results of the research carried out by Gupta and Gupta [29] showed that patients with coronary heart disease, who listened to music for 30 minutes a day for 20 days, had a significant reduction in blood pressure (both systolic and diastolic) and heart rate; listening to music reduced anxiety and symptoms of depression, increased life satisfaction, optimism and hope. The meta-analysis by Pelletier (2004), which reviewed 22 quantitative studies that examined the effects of music intervention on stress reduction by combining it with relaxation techniques, confirmed evidence that music can significantly reduce stress-related excitation [36].

Therapists who apply the RMT Guided Imagery and Music (GIM) model focus on the reduction of stress by engaging clients with somatic expressions of stress and post-traumatic stress disorder to achieve recovery and rehabilitation therapeutic goals. A randomized controlled trial "Guided Imagery and Music (GIM) with adults on sick leave suffering from workrelated stress - a mixed methods experimental study" by music therapist B. D. Beck [37] involved 20 patients experiencing stress. It showed a significant reduction in cortisol, anxiety, disturbed mood, and physical symptoms of stress, improved quality of sleep in the GIM therapy group compared to the control group. After 9 weeks of monitoring, symptoms of stress were reduced, energy and well-being rates increased in $83 \%$ of clients. According to Beck [37], it is important to provide the client with a safe and supportive environment, where one could freely express emotions and have opportunities for the spontaneous self-regulatory processes of the organism. Many MT studies emphasize the importance of therapeutic support for families, distinguishing MT with families of children with disabilities [8, 38, 39]. Active MT methods are usually applied in MT with families of children with disabilities [8, $40,41,42,43,44]$. When distinguishing the most common parents' experience - stress [2, 7, $8,9,10,11,45]$, that was emphasized by previous authors, the guidelines of RMT research for coping with stress can be applied [26, 27, 28, 29, 30, 31].

Music therapist Oldfield [38] who has many years of experience of working with children diagnosed with ASD and their parents, when analysing the experience of different music therapists working with families of children with special needs, notes that therapists focus on solving children's problems and difficulties, when parents only observe sessions. Sometimes MT takes place by involving family members in joint activities or by teaching parents the methods of musical activity that they can apply with their children at home. For music therapists, changes in the family relationship are important, improvised music creation or musical games are used in order to alleviate difficulties experienced by parents 38]. Gottfried [8]claimed that family-oriented MT literature about the assistance to parents of children with special needs, tends to single out communication difficulties that affect the interaction between parents and their children, as well as aspects of parental competence. According to Gottfried [8], it should not be limited to developing the child's emotional or communication skills, as it is important to share therapeutic experience with parents. MT helped parents to better understand their children, improved the relationship with the child. Seeing the positive reaction of children to music, the emotional process of making music, parents not only changed their approach towards the child and stereotypical attitudes towards one but they were actively involved in the process of communication. Research results recorded a positive effect of MT on families of children diagnosed with ASD, a reduction in the level of stress of parents and changes in the quality of life [8]. 
During the first weeks of quarantine, various MT institutions and associations shared public recommendations online on how to facilitate the residence during global isolation, later undertook recommendations and training for specialists in order to maintain communication and provide help to clients remotely. Among MT organizations and associations, the American Music Therapy Association (AMTA) and British Association for Music Therapy (BAMT) have been the most active in adapting to the changed situation. Specialists shared not only recommendations on the provision of services at a distance - legal nuances of providing such services, technical possibilities of using various online platforms for counselling, the peculiarities of services provided at a distance, but also provided distance learning. The BAMT website contains recommended playlists; clients, for example those with dementia, and their family members are taught to create "helping" music playlists, GIM therapists shared prerecorded works for self-help.

The theoretical analysis of the possibilities of applying RMT to families of children with developmental disabilities, revealed a small number of clinical trials in this field, especially about support to parents. The analysis and examples of provisions and principles of the research on RMT for overcoming stress suggested that the applied music therapy methods might be effective in reducing the daily stress experienced by parents raising children with developmental disorders. Taking into account recommendations and reports that emphasize the importance of maintaining therapeutic contact with clients provided by the World Health Organization and specialists during the COVID-19 quarantine, it can be argued that remote consultations is an appropriate and a necessary tool for providing therapeutic assistance not only in the period of COVID-19 pandemic, but also after it.

\section{Research methodology}

Research design based on Mixed methods and may be defined as "research in which the investigator collects and analyses data, integrates the findings and draws inferences using both qualitative and quantitative approaches or methods in a single study" [46]. Research is not restricted by the use of traditional approaches to data collection but is guided by a foundation of enquiry that underlies the research activity. Healthcare researchers may benefit from the opportunity to use such a dynamic approach to address the complex and multifaceted research problems often encountered in the health care sector. The following methods were used for the collection of research data (Table 1):

Table 1. Methods of data collection.

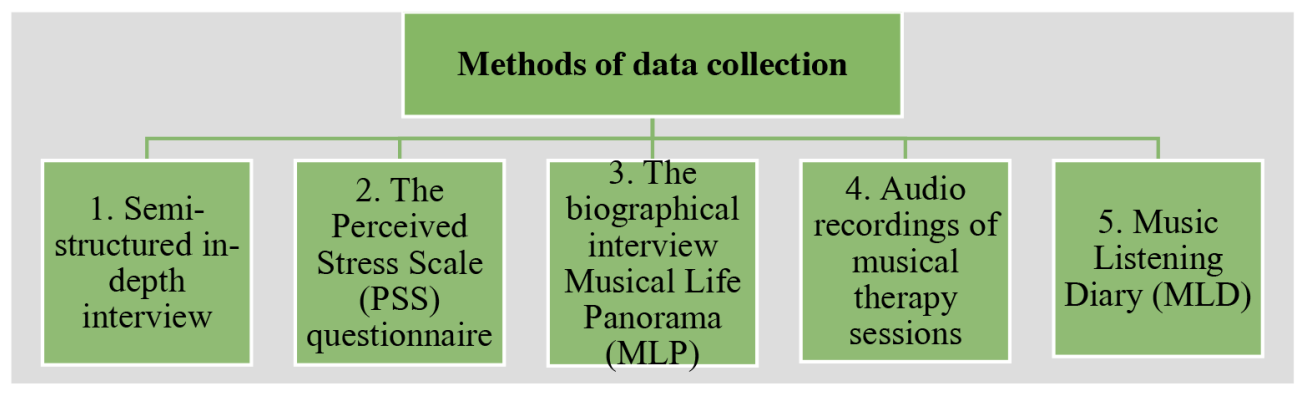

1. A semi-structured in-depth interview was applied to determine stressful situations experienced by research participants, their frequency, intensity, ability to recognize stressors and experienced feelings before and after the stressful situation, ability to deal with stress; the 
Table 2. Demographic data of research participants.

\begin{tabular}{|c|c|c|c|c|c|}
\hline $\begin{array}{c}\text { Research } \\
\text { participant }\end{array}$ & Age & Education & Maritalstatus & $\begin{array}{c}\text { Work } \\
\text { status }\end{array}$ & $\begin{array}{c}\text { Number of } \\
\text { children }\end{array}$ \\
\hline $\mathbf{D 1}$ & 40 & $\begin{array}{c}\text { Higher } \\
\text { Education }\end{array}$ & Married & Working & 2 \\
\hline $\mathbf{D 2}$ & 43 & $\begin{array}{c}\text { Higher } \\
\text { Education }\end{array}$ & Married & Not working & 2 \\
\hline $\mathbf{D 3}$ & 39 & $\begin{array}{c}\text { Higher } \\
\text { Education }\end{array}$ & Married & Working & 2 \\
\hline $\mathbf{D 4}$ & 42 & $\begin{array}{c}\text { Higher } \\
\text { Education }\end{array}$ & & Married & Working \\
\hline
\end{tabular}

content analysis method was used for the analysis of research data. Interviews were conducted live during the first individual RMT session (duration of each interview is about $1.5 \mathrm{~h}$.); having summarized the interview results, a short-term clients' therapeutic request for RMT was identified;

2. The Perceived Stress Scale (PSS) questionnaire (Cohen, 1983) scale consists of 14 questions, when subjects self-rated the level of subjectively perceived stress over the past month by choosing one of five scores on the Likert scale (from 0 - "never" to 4 - "very often");

3. The biographical interview Musical Life Panorama (MLP) (Frohne-Hagemann, 1998). The method used in an integrated music therapy as well as in the fields of psychotherapy and socio-therapy; it reveals the music experience of research participants: music-related events and memories, emotional experiences and their meanings in the biography; on the basis of the summarized data an instrument for an independent RMT application, "Musical Journey", was developed;

4. Audio recordings of musical therapy sessions - a qualitative narrative analysis of music therapy sessions to reveal the phenomenon of stress experienced by research participants, as well as its coping by using the RMT instrument. Both live and remote sessions (Zoom, Skype platforms) were recorded on a voice recorder, text analysis was conducted after transcription;

5. Music Listening Diary (MLD) - originally created table for the independent application of the RMT instrument "Musical Journey" was used by mothers each week to note the following: stressful event or situation, when they were listening to the therapeutic recording (calming down, relaxing, falling asleep, etc.); number of times they had listened. They also assessed and noted what change in the well-being, in their opinion, had taken place (if any).

Research participants. The selection of research participants was based on the principle of voluntary participation by forming a homogeneous group according to a similar experience of raising children with disabilities, age of participants with an additional criterion of not having a musical education (musical education could have complicated and prolonged the process of the RMT instrument formation). The desire to participate was expressed by six mothers, but due to the quarantine circumstances, only four of them participated in the subsequent stages of the research. 
All children with disabilities were up to seven years of age and diagnosed with autism spectrum disorder (ASD), Down syndrome, mixed developmental disorder and genetic mutation; the predominant diagnosis - ASD. A second child in one family also had an ASD disability; in another family, there was a third, a grown up child living separately. Two children attended a day care centre and a general education institution, the other two - only a day care centre.

Research ethics. During the first meeting, the participants were acquainted with the aims, course, duration of the research; written consents of the participants to take part in the research and to use research data by depersonalizing the information were obtained. Participation is voluntary, free of charge, confidentiality of participants is ensured, in accordance with the provisions of confidentiality participants were coded: D1, D2, D3, D4. With the consent of the research participants, conversations were recorded on a voice recorder and destroyed after transcription.

Organization of the research. Individual RMT sessions were to take place in February April 2020, once a week, totally 10 sessions at the X Day Care Centre for Children with Disabilities in Lithuania. However, on March 16, 2020, following the declaration of COVID-19 quarantine in the country, sessions were temporarily suspended. After two weeks, individual RMT sessions were renewed by conducting them remotely and using Skype and Zoom platforms, by adapting to the possibilities of the research participants to ensure safe and uninterrupted contact with family members. All remaining remote RMT sessions were 1 hour long. The sessions were organized according to the following structure: a) verbal part (30 min.) - devoted to the issues related to the organization of remote sessions, to the discussion of stressful experiences faced during the week, their frequency, intensity, cases of using the RMT instrument when mothers independently listened to music for self-help between sessions and filled in the "Music Listening Diary"; b) RMT application (15 min.) - listening to the "Musical Journey"; c) reflection (15 min.) - time to discuss emotions and thoughts experienced while listening to music. Seven RMT sessions took place with D1 and D4 participants, 6 sessions with D3, and 5 RMT sessions with D2. One month after the last meeting, a half-hour remote meeting was held with each participant on the Zoom platform or Skype, during which, basing on data of the completed "Music Listening Diary", possibilities of selfuse of the RMT instrument were discussed. Half a year after the last RMT session, during the second quarantine, half-hour individual remote meetings were held to discuss peculiarities of the participants' application of the RMT instrument, changes in stressful well-beings, habits of listening to music.

\section{Research results: Remote application of RMT by providing a self-help tool for coping with stress}

\subsection{Results of in-depth, semi-structured interview}

All families with children face difficulties in bringing up, caring or educating a child, but a child's disability can significantly complicate all of the mentioned. During the interview, when asked to tell what caused most stress, responses of all research participants were similar: children, household, work, interpersonal relationships, and self-assessment. After a deeper analysis, two sources of stress were identified - primary, which reveals the causes of mothers' stress due to the characteristics of the child's disability, and secondary - the experiences and neurotic behaviour of the research participants in response to stress. In the topic Stress caused by characteristics of the child's disability, the following subtopics were distinguished: communication about the child's physical and language development disorders, the child's emotional, mental development disorders and aggression, the inadequate behaviour of the child, the child's sleep disorders. Results of the semi-structured in-depth interview 
revealed causes of maternal stress that arise due to peculiarities of the child's disability (inadequate behaviour of the child, sleep disorders, aggression, limited communication). Causes of maternal stress may also be search for help and educational institutions, anxiety about the future of the child, as well as increasing social isolation of the family, deterioration of the recreational function, inability to satisfy one's hobbies, deteriorating interpersonal relationships of the family members. The psycho-emotional worries experienced by mothers tension, fatigue, despair, helplessness, anger, fear, feelings of guilt were manifested on the psychological level by stress reactions that tended to recur and caused even greater stress.

Therapeutic request. During the first meeting with the study participants, it was discussed that MT shall be short-term and it will be impossible to solve big or deep problems in ten meetings, thus it is necessary to choose the most stressful or recurring problem that we can try to understand better and learn to manage during music therapy. Three research participants (D1, D2, D3) said that they most expect help in recognizing the emotions that arise in a stressful situation and in stopping or avoiding that limit that is followed by an "explosion" - start of anger, screaming, aggression, which will later will be accompanied by feelings of guilt, despair and low self-esteem. The fourth (D4) research participant identified the development of an ability to reduce stress, which prevents from falling asleep without medications, as a therapeutic task. Having analysed the recording of the sessions and the data of the MLD filled in by research participants, one can state that the participants learned to adapt the self-help tool to alleviate the stressful situation, adverse reactions or emotions. Research participants started listening to music more often, thus improving not only their ability to relax, calm down, not get upset, reduce stress, but also their emotional state.

\subsection{Data of the Perceived Stress Scale (PSS)}

Questionnaire showed that the level of stress experienced by mothers raising children with developmental disorders was significantly higher than average. In the submitted therapeutic query, three research participants (D1, D2, D3) indicated that they expected help in recognizing emotions arising in a stressful situation, and, by independently using the RMT instrument, reduced, alleviated or avoided the experience of a stressful situation. The fourth (D4) research participant mentioned a therapeutic task of developing the ability to reduce tension, which prevents from falling asleep without medication.

\subsection{Musical Life Panorama (MLP)}

Questionnaire - the method of biographical interview revealed the musical experiences early acoustic experience, music/singing experience in childhood, place of music in the family, personal musical taste, etc. The method was used not only for the collection of data, basing on which the therapeutic self-help instrument MJ was constructed, but also as an important way to stimulate therapeutic conversation and therapeutic processes. All research participants were born at a similar time and grew up during the same period, which was not characterized by an abundance of music listening sources and a variety of repertoire. The mothers were asked an additional question, which is not included in the MLP questionnaire how they assess the sounds of nature, whether they listen to them, what kinds they like or do not. Three research participants (D1, D2, D3) claimed that they like the sounds of nature, one participant (D3) did not like the sounds of water and rain, and another (D4) liked to listen to the voices of birds. It was decided to use nature sound recordings before starting MJ, instead of relaxation carried out by the therapist.

Having analysed and summarized data of the research participants' Musical Life Panorama (MLP) biographical interview - meanings of music-related events and memories, 
emotional experiences in the biography, the main RMT tool for self-help at home was created: a 12 min. recording of musical works and sounds of nature "Musical Journey". The narrative analysis of the audio recordings of the music therapy sessions revealed research participants' stress experiences. During remote RMT sessions, listening to music induced deep emotional and psychological experiences, arisen "forgotten" events, or current painful situations that are being avoided, thus forming the basis for deep therapy for three research participants. However, given the short-term RMT envisaged in the research, the possibility of extending the resolution of deep-seated problems after the COVID-19 pandemic to a long-term RMT, was discussed with research participants.

\subsection{Narrative analysis of audio recordings of music therapy sessions}

After the start of quarantine, the structure of individual RMT sessions on the Skype and Zoom platforms remained unchanged - in the beginning a discussion of the last week's experiences and MLD (up to $30 \mathrm{~min}$.), listening to music (up to $15 \mathrm{~min}$.) and a discussion of the experience of listening to music (up to $15 \mathrm{~min}$.). During each meeting, after discussing the stressful situations experienced the previous week, research participants were asked to sit in a comfortable armchair, close their eyes, and simply listen to music without any instructions on whether to create images or not. They were also told that they could speak if they wanted to (ask to turn the music down or up or to turn it off). Having performed an analysis of the audio recordings made with a voice recorder during RMT sessions, experience of each research participant influenced by music during therapy was presented.

During the first RMT sessions, the deep emotional and psychological experiences that have evoked for three research participants while listening to music, the long-forgotten events that have emerged, or painful situations that are currently being avoided, form the basis for deep therapy. However, taking into consideration that a short-term ten-session RMT was envisaged during the research, the possibility of extending the resolution of in-depth problems after the end of the study to a long-term RMT was discussed with the participants. When continuing RMT remotely, the implementation of the therapeutic task identified during the first meeting was followed, helping research participants to better understand themselves, to recognize stressful situations, and by independently using the RMT instrument to reduce or avoid a stressful situation, and in case it is not possible to avoid it, try to facilitate its experience. All women expressed a desire for a long-term RMT.

\section{Possibilities of self-application of the RMT instrument MJ at home during the COVID-19 pandemic}

Research participants independently used the RMT instrument between weekly RMT sessions for four weeks. One month after the last RMT therapy session, all four research participants had an individual half-hour conversation, during which women recounted their stressful experiences and shared how, how many times, and when they independently applied MJ (statistics recorded by participants in the MLD are presented in parentheses).

D1. The woman independently listened to MJ to "improve her mood" (1), calm down (6), relax (4), "relax before bedtime" (1). Listening to music during meetings and independently between meetings helped to shape the habit of using the recording as a tool that helps to calm down and relax. During the last meeting, the participant of the research said: "I started listening to music more $<\ldots .>$ much more. I focused more on music as a way to calm down, of course, conversations also helped. I feel calmer a bit, I mean, given that quarantine... I thought it would be worse. I started listening at work. ., for a couple of weeks before bedtime 
I started listening to meditations". A month later. During the quarantine, the participant of the research worked, both children started attending educational institutions - school and kindergarten again, did not attend the day care centre yet, because the provision of specialist's services had not yet been resumed. The mother claimed that the most disturbing during the quarantine was the deteriorating behaviour of one of the children, but at the same time there was less stress related to children in general, because, as stated by the mother, “...I don't need to drive children anywhere, they're always at home, so that's somehow easier maybe". She claimed to be listening to the RMT instrument daily, in the evenings, in order to relax (7) or calm down (14).

The independent use of RMT helped the research participant to calm down after feeling annoyed or aggressive, to reduce the anxiety of "breaking down" and treating children in a way that would make her regret and blame oneself. Listening to MJ encouraged the research participant to listen to music more often, to search for and listen to meditative music that has a sedative effect. Calmer and better well-being can also have a positive effect on the woman's fatigue and the resulting annoyance in stressful situations caused by the behaviour of children with developmental disorders.

D2. The subject independently listened to MJ in the following cases:“...to calm down before bedtime" (4), "I wanted a break" (2), "I listened during the day" (1), "it was a sad day, I wanted to switch to something else" (1), "I simply listened" (1). She claimed that "once before bedtime I thought well tension, I need to listen to, I was listening already in bed, I was so upset. $\langle\ldots\rangle$ but I listened to the end... ). When speaking about listening to music independently, she said: "...I listened yesterday and I thought that especially now with that closed space and that stress... what I achieve with that music is like a portal to another space for me". She was glad that she learned to listen to music and think about nothing: "I can boast that I've learned... I realized how to listen to it". During the last session, the research participant claimed that she started to listen to music not alone: "Being in action, seeing the children, but emotionally I go out into my space... so it's about twelve minutes of my disconnection". The woman noted that MJ helped her create a ritual with her daughter, with whom the woman's relationship is quite complicated and very stressful. " $A$ few evenings that I do a facial massage to $D$ and for a few evenings I have turned on the waves beat or sea and I caress her face, and she liked that ritual very much... she ran to ask for the same thing again the next evening... we found it, we want to keep that ritual'. At the end of the therapy, research participant thanked "for an interesting experience" and for that, "I remembered that it is good to listen to music". After a month. When speaking about one's well-being, the woman claimed that: "probably that month was easier, less worrying about that virus. Or maybe because of the habit that it will be this way now, than I would have to go out with a mask...". The woman said "You reminded me... that music can be $<\ldots>$ I use music... to disconnect from the situation", "I deliberately started doing this by remembering our sessions $\langle\ldots>$ I use it as a method of therapy." The research participant claimed to be grateful for starting listening to music: "Thank you for giving such an idea and such... knowledge, that it's possible to bring yourself to normal state with music."

Independent listening at home encouraged to look for time for oneself, learn to "be with oneself", listening to MJ restored the pleasure of listening to music, which had been "forgotten" recently. She used the MJ sounds of nature to create a ritual with her daughter, for their pleasant time together. Relationship with the daughter is one of the stressful reasons that the research participant identified during the first meeting, during therapy, she wanted help in improving that relationship.

D3. The woman chose to listen to music independently as a background when working on a computer (2) or before bedtime (4), and to calm down (2). She monitored her reactions: “... I've got used to this melody, I hear that water, but gradually less and less. That anxiety is 
shorter, for a shorter period of time. But somehow still grasps inside...". Sometimes while listening to music the woman coloured the mandalas as one of the ways to get rid of sad thoughts or "not to think about anything". At the same time, she claimed that even though children still cause great stress, "I started to catch myself somehow, not even restrain, but now I realize that here this emotion is temporary and it will pass, so as not to be angry for the whole day or not to get upset, but to wait until it passes..." During the last meeting, the research participant stated she had received a dual benefit: “... concerning that water, I didn't realize before... now I somehow told myself and. . . discovered when it started and why. And now that I know why and what, it will be easier to understand." She started listening to music, which she almost did not do before the quarantine: "... we introduced such a new game with children, in the evening at about six o'clock we turn on Youtube and choose three songs each and we listen, father three, I three and children, and we listen to each in a row. We all stop all activities and sit down and choose music". After a month. The mother continued to work remotely, both children did not attend educational institutions, when asked about the well-being, she said that the previous month was easier and thought that "maybe I got used to", "that is most probably because of the environment, because that quarantine is softening, so maybe the environment has that effect". The research participant was glad that: "... somehow helps to be with oneself... I discover new colours... those birds, for me they bring happiness in that music...". She said she could barely hear the sounds of water that brought concerns, and when she hears real rain, "somehow there was that anxiety, but didn't reach that optimal".

Listening to MJ independently, the research participant claimed that her anxiety, when hearing the water, reduced from one hundred to twenty-five percent. When listening to music at work or before bedtime, she said being able to disconnect, which led to the perception that annoying emotions are temporary. As she began to listen to music more in general, joint activities with the family appeared, which also contributes to better and calmer relationships within the family.

D4. The subject independently listened to music, when she wanted to "learn to "disconnect" the brain, distance oneself from problems" (4) and before bedtime to help her fall asleep (1). According to the woman, she was able to relax and calm down, but she could not fall asleep. During the last session, the research participant said: "I really liked the beginning, when we started, such an awesome event of the week, to walk and come to talk and listen to music, it was something unreal"; she also said that MJ was a great discovery for her. Regarding the future application of MJ for self-help, the woman stated: "I will definitely listen to this recording again. I think that it's so very successful. When you listen more and have nothing to analyse, then it becomes so calm, and the time is good, twelve minutes, neither too little nor too much. If it was shorter, there would be a lack". After a month. The mother returned to work, children - to the kindergarten and day centre. When asked about the well-being, the woman said: “... in general, such a calm period has begun. Well, it's not calm, because there are works, but maybe my attitude, plus everything came back and was normalized. The research participant mentioned the "miracle effect" of MJ as the greatest achievement: "I know my states, I feel, I can tell when I won't fall asleep... I feel that from my muscle tone, and how things turn in my mind $<\ldots>$ it was such a hard day... I thought that I'll listen to some music, drink tea and then medications, but I listened to music and fell asleep, I woke up only in the morning. Without medication, without anything..."

The constant tendency of the research participant to analyse everything, from work to the music being listened to, caused constant stress, which turned into insomnia. During the therapy, it was discussed that it could be a sleep disorder that may require medical treatment, while music therapy could help learn to relax, calm down, which she partially succeeded in while listening to MJ. 
One month after the end of therapy, all research participants independently listened to the RMT instrument "Musical Journey" and recorded data in the "Music Listening Diary" (MLD). The data included stressful events or situations, when they listened to a therapeutic record (in order to calm down, relax, fall asleep, etc.); number of times they had listened; they also assessed and noted what change in the well-being, in their opinion, had taken place (if any). Each of the participants found the right time and form of listening to music. The results showed that usually mothers used "Musical Journey" independently in order to: calm down (22), relax (11), relax before bedtime (12), improve the mood or simply to listen (6), "disconnect" the brain, distance from problems (6). Moreover, research participants started listening to music in general and found joint musical activities with family, which determined not only better relationships between family members, but also the emotional state of all family members.

Half a year after the last RMT session, during a telephone conversation, D1, D3 and D4 claimed they were still listening to the "Musical Journey" in order to improve their wellbeing, calm down, concentrate on work. The habit of listening to music in general, formed during RMT sessions, for maintaining a good emotional state has remained. D4 noticed that she "even started listening to other music, brighter, less depressive, or fatal". D2, however, said that lately she had not listened to "Musical Journey" or any music in general, commenting that "my current life situation is too complicated, I have neither opportunities nor desire".

Limitations / peculiarities of the research. Changes and limitations caused by the quarantine have adjusted the course of the research, but the achieved results and the feedback from research participants suggest that $\mathrm{MJ}$ can be used as a self-help tool for coping with stress. The deep and complex experiences of the participants, the recognition and identification of emotions during stressful situation, which became evident during the application of the research instrument MJ, created preconditions for further in-depth long-term music therapy. When applying RMT remotely, it is important to pay attention to the peculiarities of remote counselling caused by technical issues. The therapist's ability to establish and maintain a therapeutic connection is also important. Taking into account the research results obtained with the application of remote MT, it is expected that the following will form the basis for further application of the model, not only to assist parents of children with developmental disorders, but also remotely, if necessary or with the announcement of a new quarantine.

\section{Conclusions}

1. The developed model of short-term receptive music therapy corresponds to the need identified during the empirical research to strengthen mother's stress overcoming skills. During the application of the model, the improving self-cognitive and stress coping skills reduced the risk of recurrence of stressful situations and the tension, anxiety, fear that arise from the risk of recurrence. The impact of RMT and the effectiveness of the "Musical Journey" instrument were examined by applying music therapy during remote consultations after the declaration of the COVID-19 quarantine and within one month after the end of therapy.

2. RMT research revealed that the remote application of "Musical Journey" improved the research participants' ability to recognize stressful situations better, feelings and reactions that arise during them, helped to understand their emotions better. The music therapy model for coping with stress can be applied during remote sessions by taking into account peculiarities and technical parameters of remote counselling and by ensuring security and confidentiality.

3. The clients learned to apply the therapeutic instrument independently to relieve a stressful situation, to alleviate adverse reactions or the arising emotions. During the formation of a skill to listen to music more often, not only did the ability to relax, not to get upset, and to 
calm down strengthened, but tension also decreased, and the general emotional background in the family improved. The application of RMT increased the clients' ability to cope with stress and decreased the risk of recurrence of stressful situations. Research participants confirmed the suitability of RMT both in remote sessions and in self-application of the instrument for self-help after therapy during the COVID-19 quarantine.

4. Receptive music therapy can be one of the methods of remote integrated assistance, especially during the COVID-19 pandemic. That compensates for the lack of psychological assistance and helps to maintain and improve mental health of parents of children with disabilities, thus contributing to the "Long-Term Impact of COVID-19 Pandemic on Mental Health Reduction Plan" in Lithuania (Ministry of Health, 2021).

\section{References}

[1] J. Ruškus. Negalès fenomenas. Šiauliai, Šiauliụ universiteto leidykla (2002)

[2] N. Johnson, M. Frenn, S. Feetham, P. Simpson. Autism Spectrum Disorder: Parenting Stress, Family Functioning and Health-Related Quality of Life. Families, Systems, \& Health 29(3), 232-252 (2011), DOI: 10.1037/a0025341

[3] S.J. Karst, A. Vaughan van Hecke. Parent and family Impact of autism spectrum disorders: a review and proposed model for intervention evaluation. Clinical child family psychology review 15(3), 247-277 (2012), DOI: 10.1007/s10567-012-0119-6

[4] R. Raudeliūnaitė, Ž. Rympo. Šeimụ, auginančiụ vaikus su negalia, psichosocialinè situacija. Societal Innovations for Global Growth 1(1), 849-864 (2012). Available: https://www.lituanistika.lt/content/45209

[5] A. Estes, J. Munson, G. Dawson, et al. Parenting stress and psychological functioning among mothers of preschool children with autism and developmental delay. Autism. 13(4), 375-387 (2009)

[6] S. Jurkštas, K. Pukelis. Pozityvios įtakos veiksniai šeimos nariams, ugdantiems proto negalią turinčius vaikus. Krikščioniškoji pedagogika ir psichologija, SOTER 52(80) (2014), DOI: 10.7220/2335-8785.52(80).7

[7] K. Ilias, K. Cornish, A.S. Kummar, M. Sang-Ah Park, K.J. Golden. Parenting Stress and Resilience in Parents of Children with Autism Spectrum Disorder in Southeast Asia: A Systematic Review (2018)

[8] T. Gottfried. Creating Bridges: Music-Oriented Counseling for Parents of Children with Autism Spectrum Disorder. Dissertation, Denmark, Aalborg University Press (2016) Available: https://www.psykologi.aau.dk/digitalAssets/242/242434_phd_ tali_gottfried_e-pdf_-for-print.pdf

[9] M. Meirsschauta, H. Roeyersa, P. Warreyna. Parenting in families with a child with autism spectrum disorder and a typically developing child: Mothers' experiences and cognitions. Research Group Developmental Disorders, Ghent University, H. Dunantlaan 2, B - 9000, Ghent, Belgium (2010) Available: https://core.ac.uk/download/pdf/55898279.pdf

[10] E. Predescu, R. Sipos. Cognitive coping strategies, emotional distress and quality of life in mothers of children with ASD and ADHD-A comparative study in a Romanian population sample. Open Journal of Psychiatry 3, 11-17 (2013) DOI: 10.4236/ojpsych.2013.32A003

[11] A.L. Dardas, M.M. Ahmad. Coping strategies as mediators and moderators between stress and quality of life among parents of children with autistic disorder. Stress health 31(1), p. 5-12 (2015), DOI: 10.1002/smi.2513 
[12] S. Ustilaitè, I. Kuginytė-Arlauskienè, L. Cvetkova. Šeimụ, augiančiụneigaliusvaikus, vidinioirsocialiniogyvenimopokyčiai. Socialinisdarbas 10(1), psl. 20-26 (2011). Available: https://www.lituanistika.lt/content/29599

[13] L. Šinkariova, A. Baltutienè, V. Gudonis. Tèvų, auginančiųvaikusturinčiusnegalę, depresiškumosąsajossuvaikonegalesypatumais. Specialusisugdymas 2(27), 16 (2012) Available: https://www.lituanistika.lt/content/44938

[14] S.A. Hayes, S.L. Watson. The impact of parenting stress: A meta-analysis of studies comparing the experience of parenting stress in parents of children with and without autism spectrum disorder. Journal of autism and developmental disorders 43(3), 629642 (2013). DOI: 10.1007/s10803-012-1604-y

[15] A.P. Greeff, A. Vansteenwegen, M. Ide. Resiliency in families with a member with a psychological disorder. American Journal of Family Therapy 34(4), 285-300 (2006) DOI: $10.1080 / 01926180600637465$

[16] A. Dabrowska, E. Pisula. Parenting stress and coping styles in mothers and fathers of pre-school children with autism and Down syndrome. Journal of Intellectual Disability Research 54(3), 266-280 (2010)

[17] The Department for the Affairs of Disabled under the Ministry of Social Security and Labour, Opinions of persons with disabilities in Lithuania on the assurance of rights of the disabled children and family support (2019)

[18] R. Butkevičienè. Šeimų su neigaliais vaikais problemos. Filosofija, sociologija. 1, 6271 (2001)

[19] S. Gradeckienè. Vaiko negalės įtaka visos šeimos gyvenimo kokybei. Biomedicina 2(1), 2-10 (2002)

[20] "Žmogaus studijų centras". Available: https://humanstudy.lt/naujausi-lietuvosgyventoju-emocines-bukles-tyrimo-rezultatai/ (2020)

[21] A. Narzisi. Handle the Autism Spectrum Condition during Coronavirus (COVID-19) Stay at Home Period: The tips for Helping Parents and Caregivers of Young Children. Brain Sciences (2020). DOI: 10.3390/brainsci10040207

[22] WHO, World Health Statistics, Available: https://apps.who.int/iris/bitstream/handle/ 10665/332070/9789240005105-eng.pdf (2020)

[23] UNICEF, COVID-19 and Children, Available: https://data.unicef.org/covid-19-andchildren/ (2020)

[24] SAM, Plan for Reducing the Long-Term Negative Effects of the COVID-19 Pandemic on Mental Health", Available: https://www.oecd.org/coronavirus/policy-responses/ tackling-the-mental-health-impact-of-the-covid-19-crisis-an-integrated-whole-ofsociety-response-0ccafa0b/ (2021)

[25] D. Grocke, T. Wigram. Receptive Methods in Music Therapy. Techniques and Clinical Applications for Music Therapy Clinicians, Educators and Students. London, Kingsley Publishers (2007)

[26] S.B. Hanser, S.E. Mandel. Manage your Stress and Pain through Music. Boston, USA, Berklee Press (2010)

[27] D. Vastfjall, P.N. Juslin, T. Hartig. Music, Subjective Wellbeing, and Health: The Role of Everyday Emotions/ Music, Health, and Wellbeing. MacDonald, R., Kreutz, G., Mitchell, L. Oxford Scholarship Online (2012), DOI: 10.1093/acprof: oso/9780199586974.003.0027

[28] H.C. Chang, C.H. Yu, C.H. Chen. The Effects of Music Listening on Psychosocial Stress and Maternal Fetal Attachment during Pregnancy. Complementary Therapies in Medicine 23, 509-515 (2015) 
[29] U. Gupta, B.S. Gupta. Psychophysiological reactions to music in male coronary patients and healthy controls. Psychology of Music 43, 736-755 (2015)

[30] A. Linnemann, J. Strahler, U.M. Nater. Assessing the effects of music listening on psychobiological stress in daily life. Journal of Visualized Experiments 120, e54920 (2017), DOI: $10.3791 / 54920$

[31] A. de la Torre-Luque, R.A. Caparros-Gonzalez, T. Bastard, F.J. Vico, G. Buela-Casal. Acute stress recovery through listening to Melomics relaxing music: A randomized controlled trial. Nordic Journal of Music Therapy 26, 124-141 (2017). Available: https://www.tandfonline.com/doi/abs/10.1080/08098131.2015.1131186

[32] M. de Witte, A. Spruit, S. van Hooren, X. Moonen, G.J. Stams. Effects of music interventions on stress-related outcomes: a systematic review and two meta-analyses, Health Psychology Review 14(2), 294-324 (2020), DOI: 10.1080/17437199.2019.1627897

[33] S. Koelsch, Brain and music. Oxford: John Wiley (2012)

[34] S. Hanser, The New Music Therapist's Handbook. $2^{\text {nd }}$ edition. Boston, MA: Berklee Press (1999)

[35] D. Grocke, T. Moe. Guided Imagery \& Music (GIM) and Music Imagery Methods for Individual and Group Therapy. Jessica Kingsley Publishers (2015)

[36] C. Pelletier. The effect of music on decreasing arousal due to stress: A meta-analysis. Journal of Music Therapy 41, 192-214 (2004), DOI: 10.1093/jmt/41.3.192

[37] B.D. Beck. Guided Imagery and Music (GIM) with adults on sick leave suffering from work-related stress - a mixed methods experimental study. Available: https:// vbn.aau.dk/ws/portalfiles/portal/68298949/42919_phdbolettebecksmall.pdf(2012)

[38] A. Oldfield, K. Bell, J. Pool. Three families and three music therapists: Reflections on short-term music therapy in child and family psychiatry. Nordic Journal of Music Therapy, 1-18 (2011)

[39] G. Thompson. Making a connection: Randomized controlled trial of family centered music therapy for young children with autism spectrum disorder. PhD thesis, Melbourne University, Melbourne, Australia (2012). Available: https://minervaaccess.unimelb.edu.au/handle/11343/37719

[40] A. Oldfield, Music therapy with families. Music therapy in health and education, pub. Heal M. Tigram T., London and Bristol (1997)

[41] C. Molyneux, Music Therapy as a Shotr-term Intervention with Individuals and Families in a Child and Adolescent Mental Health service. British Journal of Music therapy 19(2), UK (2005)

[42] A. Woodward, Music Therapy for Autistic Children and their Families: a Creative Spectrum. British Journal of Music therapy 18(1), UK (2004)

[43] A. Oldfield, C. Flower, Music Therapy with Children and Their Families. London and Philadelphia: Jessica Kingsley Publishers (2008)

[44] H. Loth, Music therapy Groups for families with a Learning-disabled Toddler: Bringing Some Gaps. Music Therapy with Children and Their Families, ed. Oldfield A., Flower C., London and Philadelphia: Jessica Kingsley Publishers (2008)

[45] M.M. Seltzer, J.S. Greenberg. Life Course Impacts of Parenting a Child with a Disability. American Journal on Mental Retardation 106(3), 265-286 (2001)

[46] J.W. Creswell, V. Plano Clark. Designing and Conducting Mixed Methods Research. Thousand Oaks, CA: Sage (2007) 